\title{
Correction to: On thermoelectric materials with memory-dependent derivative and subjected to a moving heat source
}

\author{
Mohamed H. Hendy ${ }^{1,2}$ - Sayed I. El-Attar ${ }^{2}$ Magdy A. Ezzat ${ }^{3,4}$
}

Published online: 12 January 2021

(C) Springer-Verlag GmbH Germany, part of Springer Nature 2021

\section{Correction to:}

Microsystem Technologies (2020)

26:595-608 https://doi.org/10.1007/ s00542-019-04519-8

The University of the corresponding author should be Department of Mathematics, College of Science and Arts, Qassim University, Al Bukairiyah, Saudi Arabia.
Publisher's Note Springer Nature remains neutral with regard to jurisdictional claims in published maps and institutional affiliations.

The original article can be found online at https:// doi.org/10.1007/s00542-019-04519-8.

Magdy A. Ezzat

maezzat2000@yahoo.com

1 Department of Mathematics, Faculty of Science, Northern

Border University, Arar, Kingdom of Saudi Arabia

2 Department of Mathematics, Faculty of Science, Al Arish University, Arish, Egypt

3 Department of Mathematics, Collegeof Science and Arts, Qassim University, Al Bukairyah, Saudi Arabia

4 Department of Mathematics, Faculty of Education, Alexandria University, Alexandria, Egypt 